\title{
Chromosome Banding in Amphibia. XXXIV. Intrachromosomal Telomeric DNA Sequences in Anura
}

\author{
Michael Schmid Claus Steinlein \\ Department of Human Genetics, University of Würzburg, Würzburg, Germany
}

\section{Key Words}

Anura - Euchromatin - Evolutionary fixation .

Heterochromatin · Intrachromosomal telomeric sequences distribution in the karyotypes and evolutionary fixation in the genomes, as well as their cytological detection are discussed.

(c) 2016 S. Karger AG, Basel

\begin{abstract}
The mitotic chromosomes of 4 anuran species were examined by various classical banding techniques and by fluorescence in situ hybridization using a (TTAGGG) ${ }_{n}$ repeat. Large intrachromosomal telomeric sequences (ITSs) were demonstrated in differing numbers and chromosome locations. A detailed comparison of the present results with numerous published and unpublished data allowed a consistent classification of the various categories of large ITSs present in the genomes of anurans and other vertebrates. The classification takes into consideration the total numbers of large ITSs in the karyotypes, their chromosomal locations and their specific distribution patterns. A new category of large ITSs was recognized to exist in anuran species. It consists of large clusters of ITSs located in euchromatic chromosome segments, which is in clear contrast to the large ITSs in heterochromatic chromosome regions known in vertebrates. The origin of the different categories of large ITSs in heterochromatic and euchromatic chromosome regions, their mode of
\end{abstract}

In addition to their obligatory location at chromosomal termini, the canonical telomeric (TTAGGG) $)_{n}$ repeats are also encountered at internal sites of the chromosomes, the so-called intrachromosomal or interstitial telomeric sequences (ITSs). Up to date, 2 categories of ITSs were recognized to exist in vertebrate genomes: (1) short ITSs (s-ITSs), that are composed of a few to as many as a few hundred base pairs of (TTAGGG) $)_{n}$ repeats and are scattered over all chromosomes, but seem to accumulate in some subterminal regions, and (2) large ITSs in heterochromatic chromosome regions (het-ITSs) that can span up to several hundred kilobases. Whereas het-ITSs are non-obligatory components of the karyotypes, s-ITSs are presumably present in all vertebrate genomes. Very detailed studies using FISH [Azzalin et al., 1997], molecular cloning [Azzalin et al., 2001], and exploration of the human genome database [Nergadze et al., 2007] have disclosed the number, chromosomal location and molecular

\section{KARGER}

E-Mail karger@karger.com www.karger.com/cgr
(C) 2016 S. Karger AG, Basel

$1424-8581 / 16 / 1483-0211 \$ 39.50 / 0$ 
organization of s-ITSs in the human genome. s-ITSs have also been demonstrated in the genomes of other primates [Azzalin et al., 2001; Ruiz-Herrera et al., 2002, 2005; Nergadze et al., 2004] and rodents [Faravelli et al., 1998, 2002; Camats et al., 2006; Nergadze et al., 2007]. Some of the s-ITSs in mammalian chromosomes are subtelomeric repeats and are arranged as head-to-tail tandem arrays. They contain many degenerate units that supposedly have originated by recombination that involved telomeric regions [Azzalin et al., 2001; Nergadze et al., 2007]. Eighty-three of such s-ITSs have been detected in the human genome, 244 in the mouse, 250 in the rat, and 79 in the chimpanzee [Nergadze et al., 2007]. Experimental molecular data strongly suggest that, during evolution, mammalian s-ITSs have been inserted at internal chromosome sites in a 1-step event in the germline. The insertions have been mediated by the repair of DNA double strand breaks [for review, see Ruiz-Herrera et al., 2008].

No attempts were made up to date to demonstrate the existence and chromosomal locations of s-ITSs in amphibians, although there are no obvious reasons why such sequences should be absent in amphibian genomes. The mandatory precondition for a systematic search of s-ITSs requires hundreds of high-quality metaphases derived from single amphibian specimens, and also the production of multiple banding patterns along their chromosomes that would allow the exact positioning of s-ITS signals with FISH. However, as well-known by amphibian cytogeneticists, the induction of sharp multiple banding patterns along amphibian chromosomes is technically problematic [for review, see Schmid et al., 2010].

As in the chromosomes of all other vertebrates examined with FISH and (TTAGGG) $)_{n}$ repeats, the het-ITSs in anuran genomes are always components of the repetitive DNA in the classical constitutive heterochromatin. This heterochromatin is located in the centromeric, pericentromeric or interstitial regions of the chromosomes. In some instances, het-ITSs are components of the heterochromatin associated with nucleolus organizer regions (NORs).

Large ITSs were already detected in 43 anuran species belonging to the families Centrolenidae (genus Vitreorana, 1 species), Dicroglossidae (genus Quasipaa, 1 species), Hylidae (genera Aplastodiscus, 4 species; Hyla, 5 species; Hypsiboas, 4 species; Itapotihyla, 1 species; Phyllodytes, 1 species; Pseudacris, 2 species; Scarthyla, 1 species; Sphaenorhynchus, 2 species), Leptodactylidae (genus Leptodactylus, 3 species), Pelodryadidae (genera Dryopsophus, 3 species; Litoria, 2 species), Phyllomedusidae (genera Agalychnis, 1 species; Phyllomedusa, 5 species),
Pipidae (genus Xenopus, 4 species), and Strabomantidae (genus Pristimantis, 3 species). These species and the corresponding studies are compiled in table 1 (see Discussion).

In the present study, large ITSs were demonstrated in 4 further anuran species belonging to the families Hylidae and Pelodryadidae, and the need for a consistent classification of the various categories of large ITSs present in the genomes of anurans and other vertebrates was realized. A classification is proposed which takes into account (1) the total number of large ITS clusters in the genomes, (2) their specific chromosomal locations and (3) their distribution patterns in the karyotypes of the individual species. A new category of large ITSs has been recognized to exist in anuran species. It consists of large clusters of ITSs located in euchromatic chromosome segments, which is in clear contrast to the large het-ITSs found in vertebrates. The origin of the different categories of large ITSs in heterochromatic and euchromatic chromosome regions, their evolutionary fixation in the genomes, as well as their cytogenetic detection are discussed.

\section{Materials and Methods}

\section{Animals}

Adult individuals of the following anuran species were collected: Dryopsophus genimaculatus (Mount Lewis, Queensland; $16^{\circ} 34^{\prime} \mathrm{S} / 145^{\circ} 16^{\prime} \mathrm{E}$ ), D. australis (Adelaide River, Northern Territory; $12^{\circ} 39^{\prime} \mathrm{S} / 131^{\circ} 19^{\prime} \mathrm{E}$ ), Hypsiboas faber (near Itanhaém, São Paulo State, Brazil; $24^{\circ} 10^{\prime} \mathrm{S} / 46^{\circ} 47^{\prime} \mathrm{W}$ ), H. boans (at $\mathrm{km} 99$ on the road from El Dorado to Santa Elena de Uairén, Bolivar State, Venezuela; $\left.06^{\circ} 04^{\prime} \mathrm{N} / 61^{\circ} 24^{\prime} \mathrm{W}\right)$. The chromosomes of the frogs were prepared in the Northern Territory Museum (Darwin, Australia), the Evolutionary Biology Unit of the South Australian Museum (Adelaide, Australia), the Instituto Butantan, University of São Paulo (São Paulo, Brazil), and in the field station 'Estación Biológica de Rancho Grande' located in the Henri Pittier National Park (Aragua State, Venezuela). The fixed material was transferred to $1.8-\mathrm{ml}$ plastic tubes (Nunc), stored at $4^{\circ} \mathrm{C}$ and transported to the laboratory in Würzburg (Germany) for cytogenetic analyses.

\section{Chromosome Preparations}

Mitotic chromosomes were prepared directly from the bone marrow after in vivo colchicine treatment. Detailed techniques used for cell suspensions, as well as the hypotonic treatment and fixation of the cells have been described previously [Schmid et al., 2010].

\section{Banding Analyses and FISH}

C-banding, fluorescence staining with quinacrine mustard, DAPI or Hoechst 33258, fluorescence counterstaining with distamycin A/mithramycin and distamycin A/DAPI, and labeling of the NORs with $\mathrm{AgNO}_{3}$ were performed according to the methods described by Schmid et al. [2010]. For the detection of the 


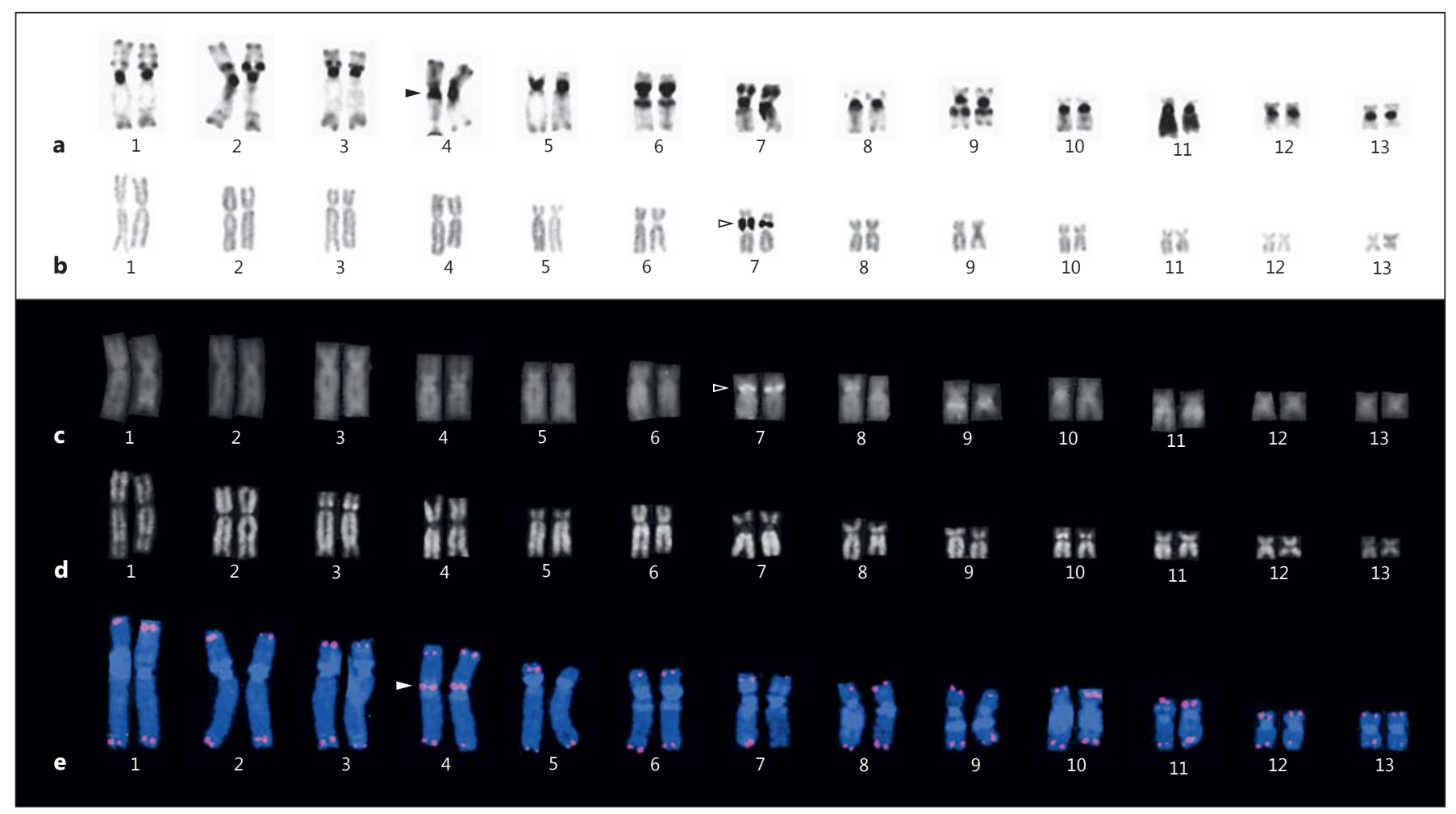

Fig. 1. Karyotypes of Dryopsophus genimaculatus showing C-banding (a), silver labeling (b), distamycin A/mithramycin counterstaining $(\mathbf{c})$, quinacrine mustard fluorescence $(\mathbf{d})$, and FISH with the telomeric DNA probe (e). The single large restricted het-ITS in the centromeric heterochromatin of chromosome 4 is indicated by filled arrowheads and the NOR by open arrowheads.

$\left(5^{\prime}-\mathrm{TTAGGG}-3^{\prime}\right)_{\mathrm{n}}$ telomeric repeats, a fluorescein-conjugated peptide nucleic acid (PNA) probe (Telomere PNA FISH kit/FITC; Dako Cytomation, Denmark; K5325) was used. Detailed procedures for in situ hybridization and signal detection are provided by the manufacturer.

\section{Microscopic Analyses}

Microscopic analyses were conducted using Zeiss photomicroscopes III, fluorescence microscopes and Axiophot microscopes equipped with incident $\mathrm{HBO} 50 \mathrm{~W}$ mercury lamp illumination. The filter combinations necessary for the analyses of metaphases stained with the various fluorochromes or for FISH were described by Schmid et al. [2010].

\section{Results}

\section{Large ITSs in Restricted Heterochromatic Regions \\ (Restricted het-ITSs)}

The majority of large ITSs found in the genomes of anurans and other vertebrates are located in only 1 or some few heterochromatic regions present in their karyotypes. Here, these are defined as 'large ITSs in re- stricted heterochromatic regions (restricted het-ITSs)'. They are always distributed in a random manner to a subset of the heterochromatic regions present in the karyotypes. All remaining heterochromatic regions are devoid of microscopically recognizable het-ITSs. As examples of such restricted het-ITSs, the karyotypes of 2 frog species belonging to the Australian family Pelodryadidae are presented here. In D. genimaculatus, a single restricted het-ITS is found in the centromeric heterochromatin of chromosome 4 (fig. 1e). Fluorescence stainings with the GC base pair-specific mithramycin (fig. 1c) and the AT base pair-specific quinacrine mustard (fig. 1d) indicate that this restricted het-ITS is embedded in GC-rich heterochromatin. In D. australis, a total of 8 restricted het-ITSs are detectable in centromeric and interstitial heterochromatic regions of chromosomes 1, 3, 5, and 9-12 (fig. 2e). Again, the specific fluorescence labelings with mithramycin (fig. 2c) and quinacrine mustard (fig. 2d) reveal that the restricted het-ITSs in the long arms of chromosomes 3 and 11 of this species are positioned in GC-rich heterochromatin. 


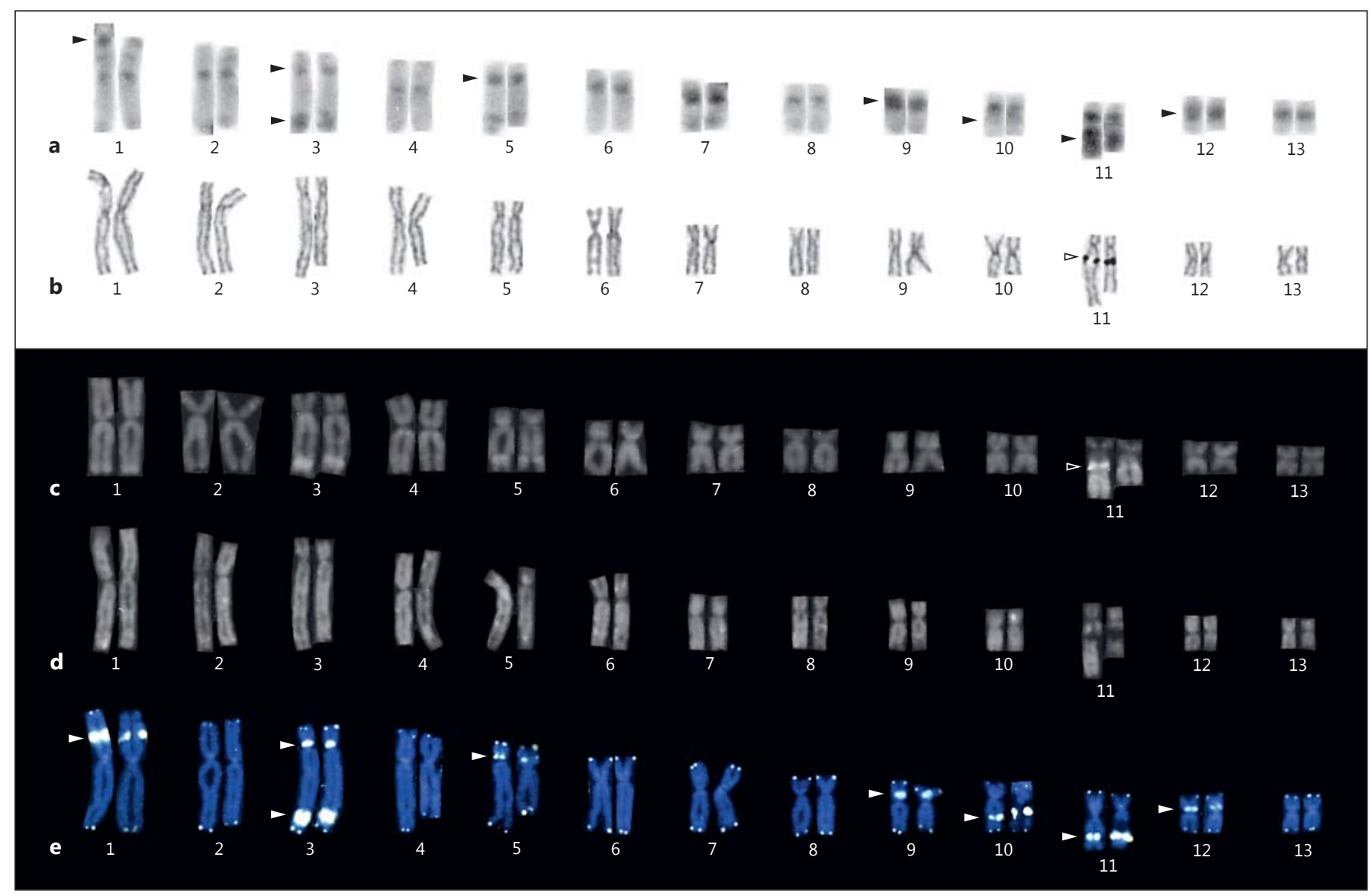

Fig. 2. Karyotypes of Dryopsophus australis showing C-banding (a), silver labeling (b), distamycin A/mithramycin counterstaining (c), quinacrine mustard fluorescence (d), and FISH with the telomeric DNA probe (e). The 8 large restricted het-ITSs in centromeric and/or interstitial heterochromatic regions of chromosomes 1, 3, 5, and 9-12 are indicated by filled arrowheads and the NOR by open arrowheads.

The restricted het-ITS in chromosome 11 is located in NOR-associated heterochromatin (fig. 2b, c, e). The heterochromatic regions of the other restricted het-ITSs are not specifically labeled by mithramycin or quinacrine mustard. It is feasible that in these heterochromatic regions equal amounts of $\mathrm{AT}$ and GC pairs are present in the repetitive sequences, so that none of the DNA base pair-specific fluorochromes produces differential labeling [for review, see Schmid et al., 2010].

The further anuran species in whose genomes restricted het-ITSs were discovered up to date are listed in table 1. Apparently, there is no obvious rule how these restricted het-ITSs are distributed in the karyotypes. They colocalize randomly with 1 or some few heterochromatic regions located in autosomes or sex chromosomes, in supernumerary B chromosomes, in centromeric or interstitial positions, in short and/or long chromosome arms, in some cases at NORs. Their numbers range from 2 to 16 per diploid karyotype.

In different populations of the same species, dissimilarities in the number and chromosomal position of restricted het-ITSs can occur. Hence, in the specimens of Phyllomedusa distincta examined by Bruschi et al. [2014], restricted het-ITSs are located in the heterochromatic centromeric regions of chromosomes 8 and 11, whereas in the individuals studied by Gruber et al. [2013], these are found in the centromeric regions of chromosomes 6, 7 and 11 (table 1). However, the possibility that these frogs actually belong to 2 different cryptic species should not be ignored.

Interestingly, in a single analyzed individual of $\mathrm{Ag}$ alychnis callidryas (family Phyllomedusidae) collected in Costa Rica, the restricted het-ITSs in the centromeric regions of chromosomes 1 and 7 as well as in the short arms 


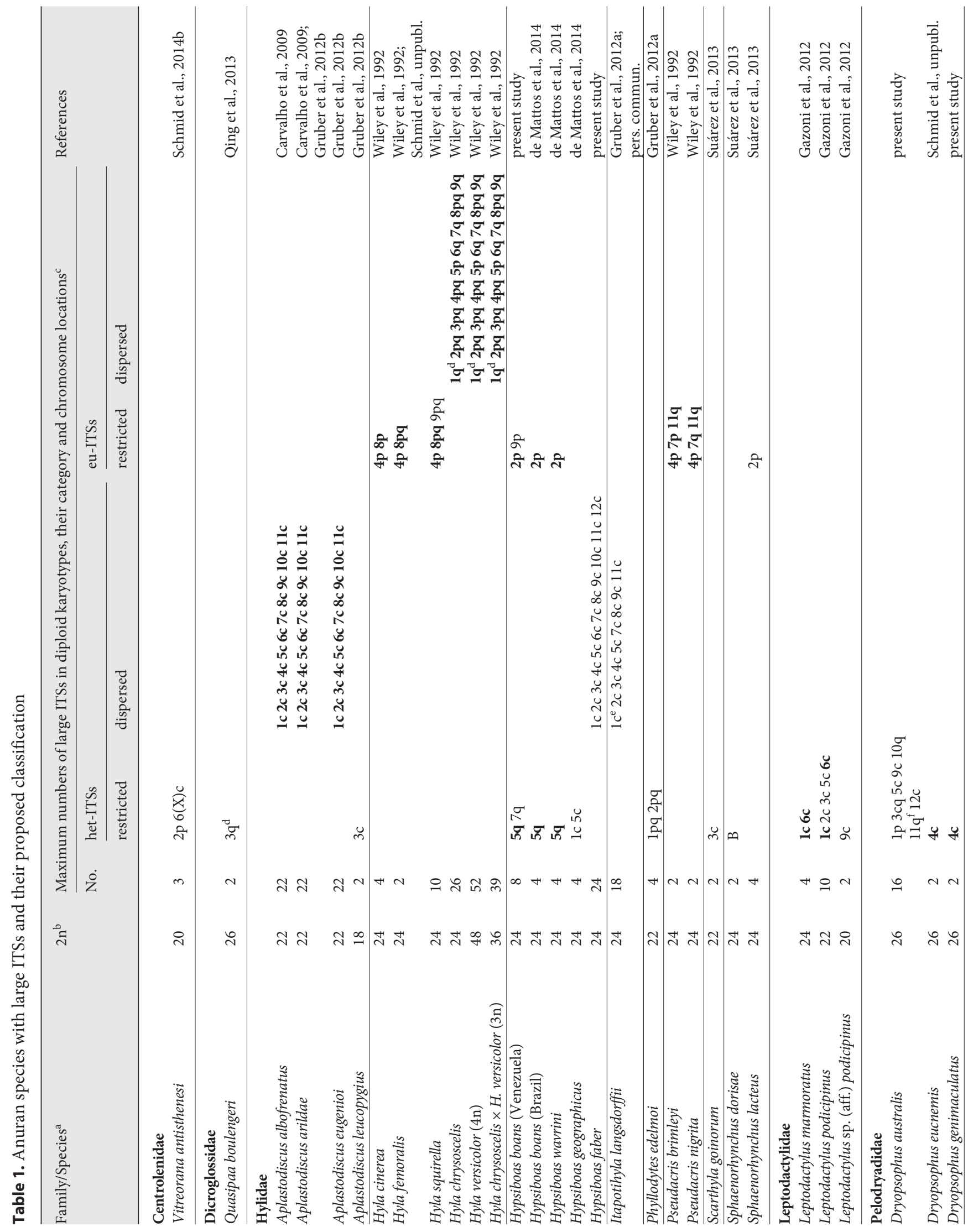




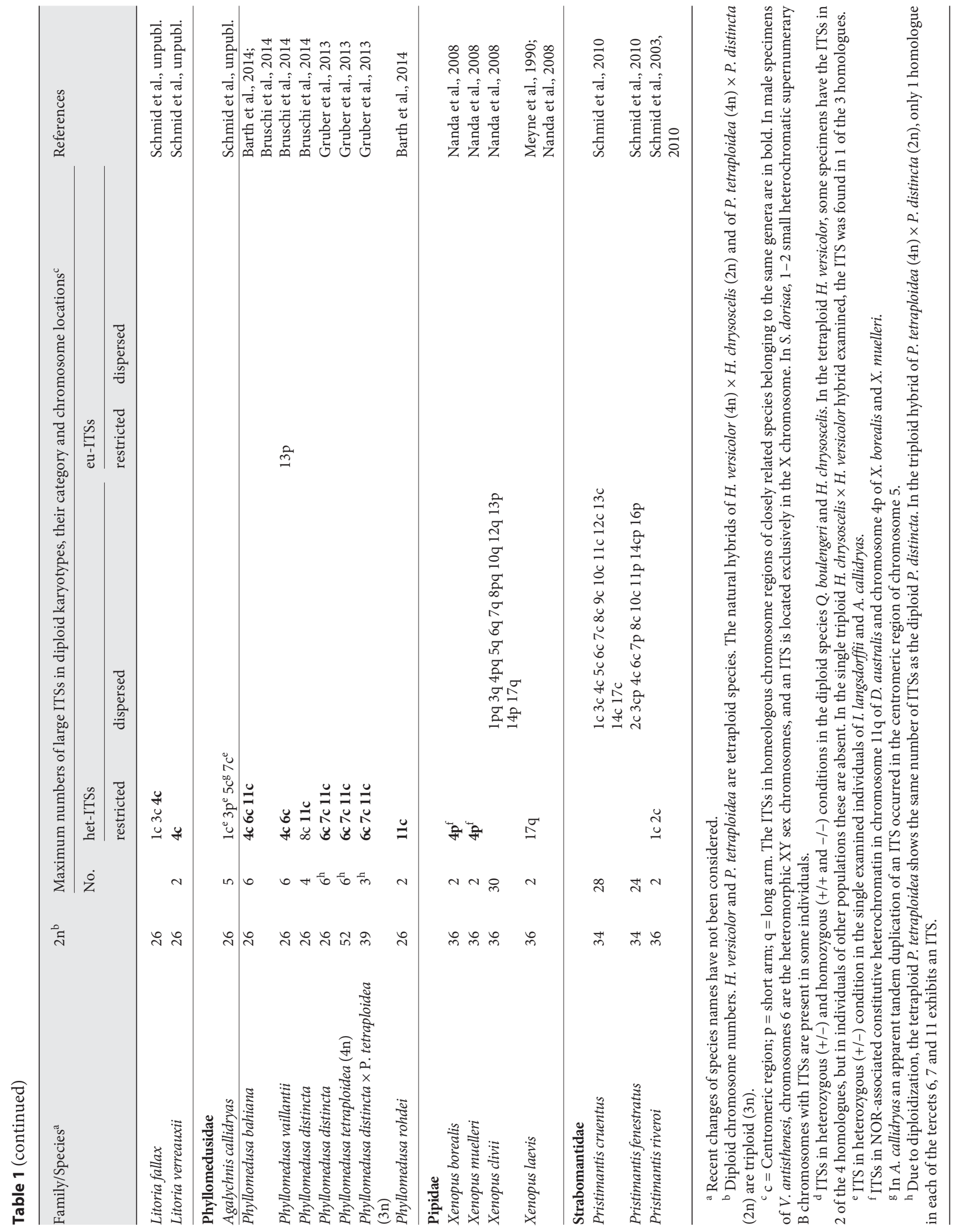


of chromosome 3 occur in heterozygous (+/-) condition (table 1). This could indicate that these restricted het-ITSs are of more recent evolutionary origin. Whether such heterozygous restricted het-ITSs are finally fixed in, or eliminated from, a population by non-directional and accidental fluctuations of the frequencies of the homologues with and without restricted het-ITSs, is determined by the size of the population, the genetic flow between neighboring populations, and the selective neutrality of the restricted het-ITSs (genetic drift). It would be interesting to examine a representative number of A. callidryas specimens in that Costa Rican population with the (TTAGGG) $)_{\mathrm{n}}$ repeat in order to determine the degree of heterozygosity (+/-) and homozygosity (+/+ and $-/-)$ of these restricted het-ITSs. In the same individual of $A$. callidryas, a possible tandem duplication of a restricted het-ITS was apparent in the centromeric heterochromatin of chromosome 5 (table 1). The 2 resulting restricted het-ITSs are located in a mirror-like position on both sides of the centromeric constriction. Such duplicated ITSs were not observed in further anuran species.

In individuals of Quasipaa boulengeri (family Dicroglossidae), collected in 2 populations in China, a possible restricted het-ITS exists in the proximal region of the chromosome 3 long arm. This ITS occurs in heterozygous $(+/-)$ and homozygous $(+/+$ and $-/-)$ conditions (table 1). The number of specimens analyzed is, however, not sufficient to calculate whether the 3 morphs of chromosome 3 are in Hardy-Weinberg equilibrium in these populations. Furthermore, C-banding was not performed in Q. boulengeri [Qing et al., 2012, 2013]. Therefore, it is unknown whether this ITS is actually located in constitutive heterochromatin and, in turn, if it represents a genuine het-ITS.

It becomes apparent that in several related species belonging to the same genera nearly all restricted het-ITSs are located in homeologous chromosome regions (table 1). For example, in Phyllomedusa bahiana, P. vaillantii, P. distincta, P. tetraploidea, and P. rohdei, the majority of restricted het-ITSs have homeologous positions. Therefore, it seems likely that these restricted het-ITSs were already present in the common ancestor of these taxa and remained evolutionarily conserved during karyotype phylogeny.

An unexpected discovery was made by Gruber et al. [2013] in P. tetraploidea. This tetraploid species $(4 n=52)$ probably originated from the closely related diploid $P$. distincta $(2 \mathrm{n}=26)$ or, alternatively, from a common diploid ancestor of both species by autopolyploidy [Pombal and Haddad, 1992; Brunes et al., 2010]. The 2 species oc-

Chromosome Banding in Amphibia. XXXIV. ITSs in Anura cur sympatrically in some populations in southeastern Brazil where natural interspecies crosses yield viable triploid hybrids. In the diploid $P$. distincta, 6 restricted hetITSs were found in the centromeric heterochromatin of chromosome pairs 6, 7 and 11. Although in the tetraploid $P$. tetraploidea 12 restricted het-ITSs were supposed to exist in the chromosome quartets 6,7 and 11, the same situation as in the diploid P. distincta was encountered. In only 2 homologues each of the quartets 6,7 and 11 , the restricted het-ITSs were detected, but the other homologues showed no centromeric hybridization. In the triploid $P$. distincta $\times P$. tetraploidea hybrid, only 1 homologue in each of the tercets 6,7 and 11 contained the restricted het-ITSs (table 1). Gruber et al. [2013] interpreted this interesting finding as the result of an ongoing diploidization process in the genome of P. tetraploidea. This was corroborated by their analyses of the C-banding patterns which revealed conspicuous differences within some quartets of $P$. tetraploidea that divide each of these quartets into 2 pairs of homologous chromosomes. The diploidization process operating in polyploid genomes causes a divergent development of originally identical chromosomes and genes. It leads to a strict formation of bivalents in meiosis and disomic segregation rates [Ohno, 1970; Leipoldt, 1983; Gregory and Mable, 2005]. Diploidization causes genomes, which are polyploid with respect to the amount of genetic material and the number of gene copies, to become diploid with respect to the level of gene expression and various chromosomal characteristics. Diploidization is believed to have been one of the most important processes that stabilized the selective advantages produced by polyploidization and that contributed to the creation of new gene loci [Ohno, 1970]. If $P$. tetraploidea originated by autopolyploidy from $P$. distincta or from a common diploid ancestor of both species, its original genome must have contained 12 restricted het-ITSs in the chromosome quartets 6,7 and 11 . Subsequently 2 restricted het-ITSs in each of these 3 quartets were selectively lost during the process of diploidization. The mechanism that eliminated these repetitive (TTAGGG) ${ }_{n}$ repeats from the centromeric regions is unknown, but it is well-known that sequence changes in repetitive DNAs can occur and be fixed in genomes at an evolutionarily high pace.

\section{Large ITSs in Dispersed Heterochromatic Regions (Dispersed het-ITSs)}

A more exceptional pattern of het-ITSs, referred here to as 'large ITSs in dispersed heterochromatic regions (dispersed het-ITSs)', is found in the genomes of some 


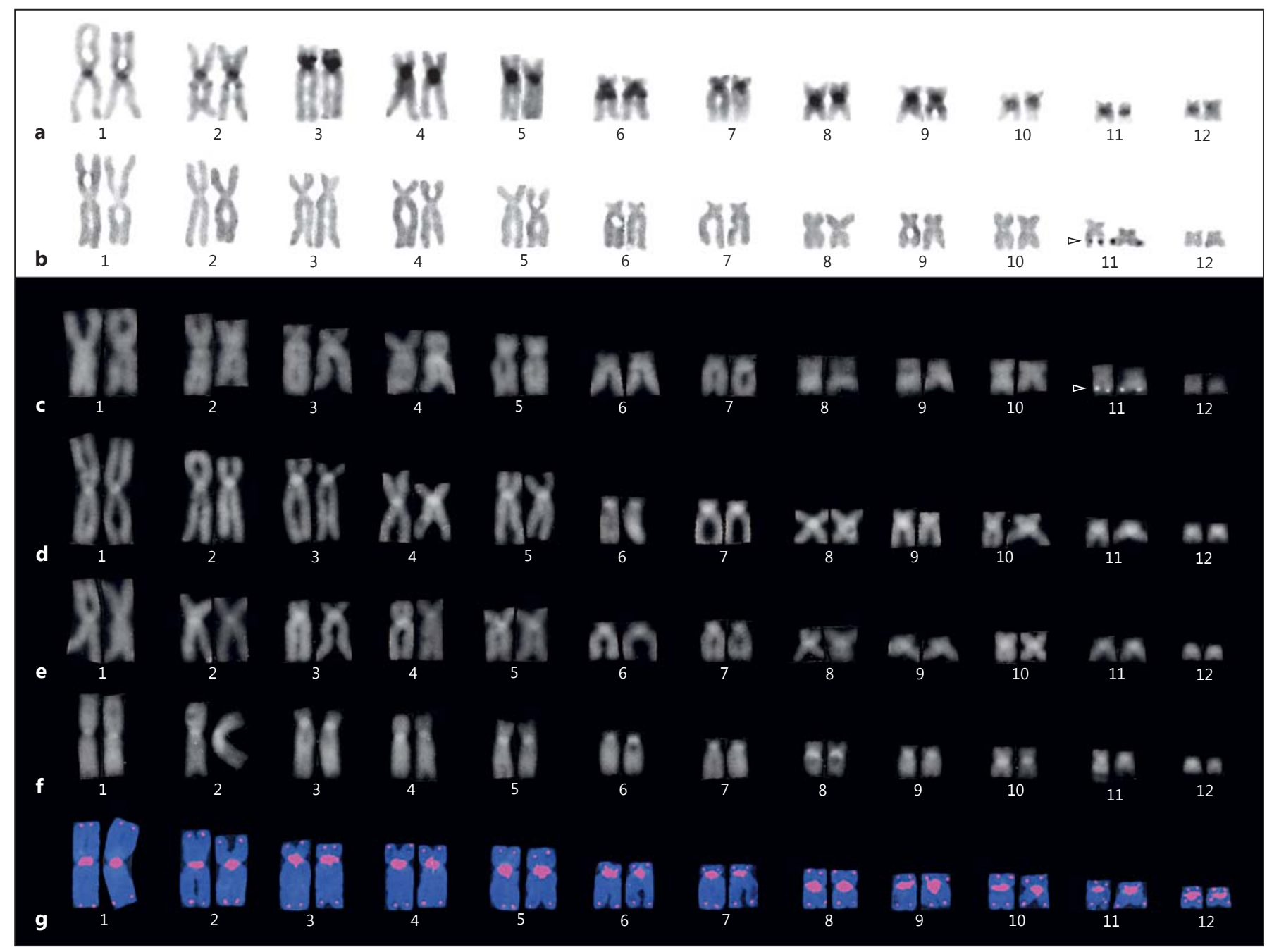

Fig. 3. Karyotypes of Hypsiboas faber showing C-banding (a), silver labeling (b), distamycin A/mithramycin counterstaining (c), quinacrine mustard fluorescence (d), DAPI fluorescence (e), Hoechst 33258 fluorescence (f), and FISH with the telomeric DNA probe $(\mathbf{g})$. Note the large dispersed het-ITSs in the centromeric heterochromatin of all 12 chromosome pairs. The NOR is indicated by open arrowheads.

anurans and other vertebrates. As an example of this category, the karyotype of the neotropical frog H. faber (family Hylidae) is reported in the present study. In this Brazilian species, the heterochromatic centromeric regions of all 12 chromosome pairs are completely labeled after FISH with the telomeric DNA probe (fig. 3g). These dispersed het-ITSs perfectly colocalize with the centromeric heterochromatin in all chromosomes, and do not extend into the adjacent pericentromeric heterochromatin present in chromosomes 3,6 and 9. As shown by fluorescence staining with the GC base pair-specific fluorochrome mithramycin and the AT base pair-specific fluorochromes quinacrine mustard, DAPI, and Hoechst 33258, all dispersed het-ITSs of $H$. faber are located in AT-rich repetitive DNA sequences (fig. $3 c-f)$. There are no interstitial het-ITSs or NOR-associated het-ITSs in the karyotype of this species.

The other anurans in whose genomes dispersed hetITSs could be recorded are compiled in table 1. In these species, many dispersed het-ITSs colocalize with all or the majority of heterochromatic centromeric regions. Thus, like in $H$. faber, large dispersed het-ITSs are located in the constitutive heterochromatin of all centromeric regions in the karyotypes of the 3 hylid species Aplastodiscus al- 
bofrenatus, A. arildae and A. eugenioi. With all probability, the dispersed het-ITSs in these closely related Aplastodiscus taxa can be traced back to a common ancestral karyotype. In the Brazilian hylid Itapotihyla langsdorffii and the Costa Rican strabomantid Pristimantis cruentus, 18 of 24 and 28 of 34 heterochromatic centromeric regions, respectively, are endowed with dispersed het-ITSs. In the single specimen of I. langsdorffii examined, the dispersed het-ITS in the chromosome 1 centromeric region was found in heterozygous (+/-) condition.

Another distribution pattern of dispersed het-ITSs in karyotypes of anurans and other vertebrates is their location in multiple interstitial heterochromatic regions which are often at equilocal or nearly equilocal sites in heterologous chromosomes. This pattern exists in the karyotype of the African clawed frog Xenopus clivii which exhibits 30 dispersed het-ITSs in a total of 12 chromosome pairs (table 1). Finally, a mixed distribution pattern of dispersed het-ITSs in the heterochromatin of centromeric as well as interstitial positions was found in the karyotype of the neotropical strabomantid Pristimantis fenestratus. In this species, 7 centromeric and 5 interstitial dispersed het-ITSs occur in 10 chromosome pairs (table 1).

In conclusion, unlike restricted het-ITSs, dispersed het-ITSs occur in much higher number in the karyotypes and are not distributed randomly among the heterochromatic regions. Instead, they occupy the complete or nearly complete set of heterochromatic centromeric or interstitial regions, or show high rates of presence in both. Admittedly, an exact differentiation between restricted and dispersed het-ITSs turns out to be difficult in some species. For example, the 16 restricted het-ITSs in the karyotype of $D$. australis $(2 \mathrm{n}=26$; fig. $2 \mathrm{e})$ could be classified as dispersed het-ITSs as well if only their absolute number is considered. However, the apparent random location in the karyotype forces their classification as restricted hetITSs.

\section{Large ITSs in Restricted Euchromatic Regions (Restricted eu-ITSs)}

A new category of ITSs, which is in clear contrast to the known classes of ITSs in vertebrate genomes, was recognized in the present study and defined as 'large ITSs in restricted euchromatic regions (restricted eu-ITSs)'. In the short arms of chromosome pairs 2 and 9 of the frog $H$. boans collected in southern Venezuela, very large ITSs are detectable which are embedded in non-heterochromatic (euchromatic) chromosome segments (fig. 4a, i). This is especially evident in preparations that were first

Chromosome Banding in Amphibia.

XXXIV. ITSs in Anura hybridized in situ with the telomeric DNA probe and subsequently subjected to C-banding, which allows a direct comparison of FISH signals and C-band patterns in the same chromosomes (fig. 5). More than half of the euchromatin in the short arm of chromosome 2 and the complete euchromatic short arm of chromosome 9 consist of ITSs. C-banding reveals that both chromosome segments are not heterochromatic (figs. 4a, 5b, d). Furthermore, staining with AT and GC base pair-specific fluorochromes as well as distamycin A/DAPI counterstaining also failed in demonstrating constitutive heterochromatin in both chromosome segments (fig. 4c-g).

In $H$. boans, 1 further very small ITS can be recognized in the middle of the long arms of chromosome pair 7 (fig. $5 \mathrm{a}, \mathrm{c}$ ), but this one is a genuine restricted het-ITS located in the NOR-associated heterochromatin (fig. 4a, b). Finally, in some preparations, a tiny ITS which may be associated with a small interstitial C-band can be recognized close to the genuine telomeric (TTAGGG) ${ }_{n}$ repeats in the long arms of chromosome pair 5 (fig. 5a).

De Mattos et al. [2014] examined the metaphase chromosomes of 7 Hypsiboas species, from the Amazonas State in Brazil using conventional staining, C-banding, silver staining, and FISH with telomeric DNA probes. Three of these species, $H$. boans, $H$. wavrini and $H$. geographicus are closely related and included in the H. semilineatus species group. The single male $H$. boans they analyzed was collected in São Sebastião do Uatumã. This locality is $\sim 1,200 \mathrm{~km}$ (bee-line) apart from the site in Venezuela where the male $H$. boans studied here was sampled. The karyotypes in both $H$. boans populations are very similar concerning gross chromosome morphology, but differences exist in the C-banding patterns and location of the NORs. In the Brazilian H. boans population, the conspicuous large restricted eu-ITS in the short arm of chromosome 2 and the tiny ITS close to the telomeric (TTAGGG) ${ }_{n}$ repeats in the long arms of chromosome pair 5 are also present. However, the large restricted eu-ITS in the short arm of chromosome 9 is clearly absent (table 1). The same situation was encountered in $H$. wavrini. The similar patterns of ITSs, C-bands and chromosomal localization of NORs in the Brazilian $H$. boans and $H$. wavrini confirm the close phylogenetic relationship of both species [Faivovich et al., 2005]. Finally, in $H$. geographicus, 2 restricted het-ITSs are located in the centromeric heterochromatin of chromosomes 1 and 5, but no eu-ITSs are present in this species (table 1).

Interestingly, de Mattos et al. [2014] did not realize that the ITSs present in the genomes of $H$. boans and $H$. wavrini differ from the the well-known category of 


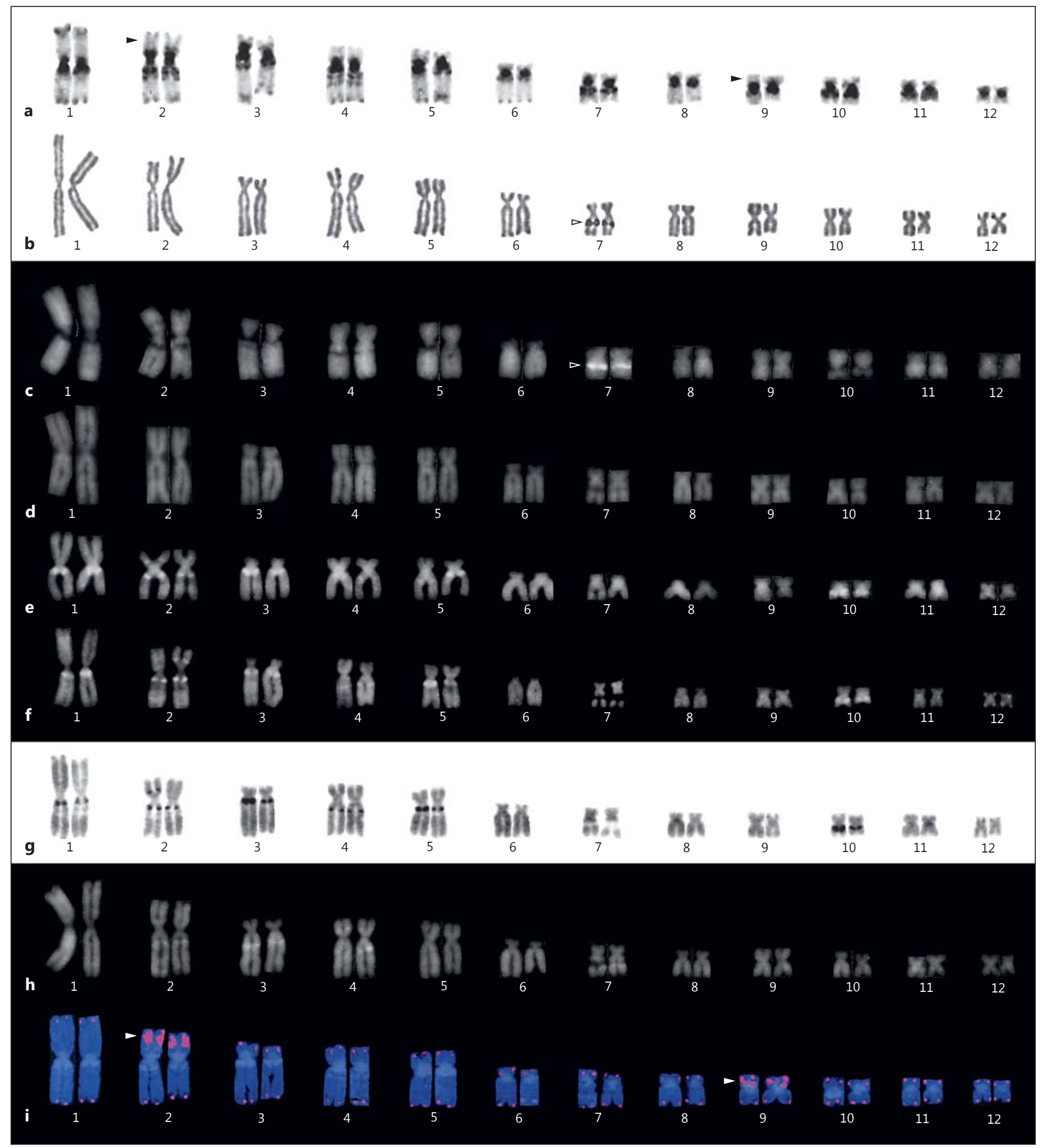

Fig. 4. Karyotypes of Hypsiboas boans showing C-banding (a), silver labeling (b), distamycin A/mithramycin counterstaining (c), quinacrine mustard fluorescence (d), DAPI fluorescence (e), Hoechst 33258 fluorescence (f), inverted Hoechst 33258 fluorescence (g), distamycin A/DAPI counterstaining (h), and FISH with the telomeric DNA probe (i). The 2 large restricted eu-ITSs in the short arms of chromosomes 2 and 9 are indicated by filled arrowheads and the NOR by open arrowheads. 


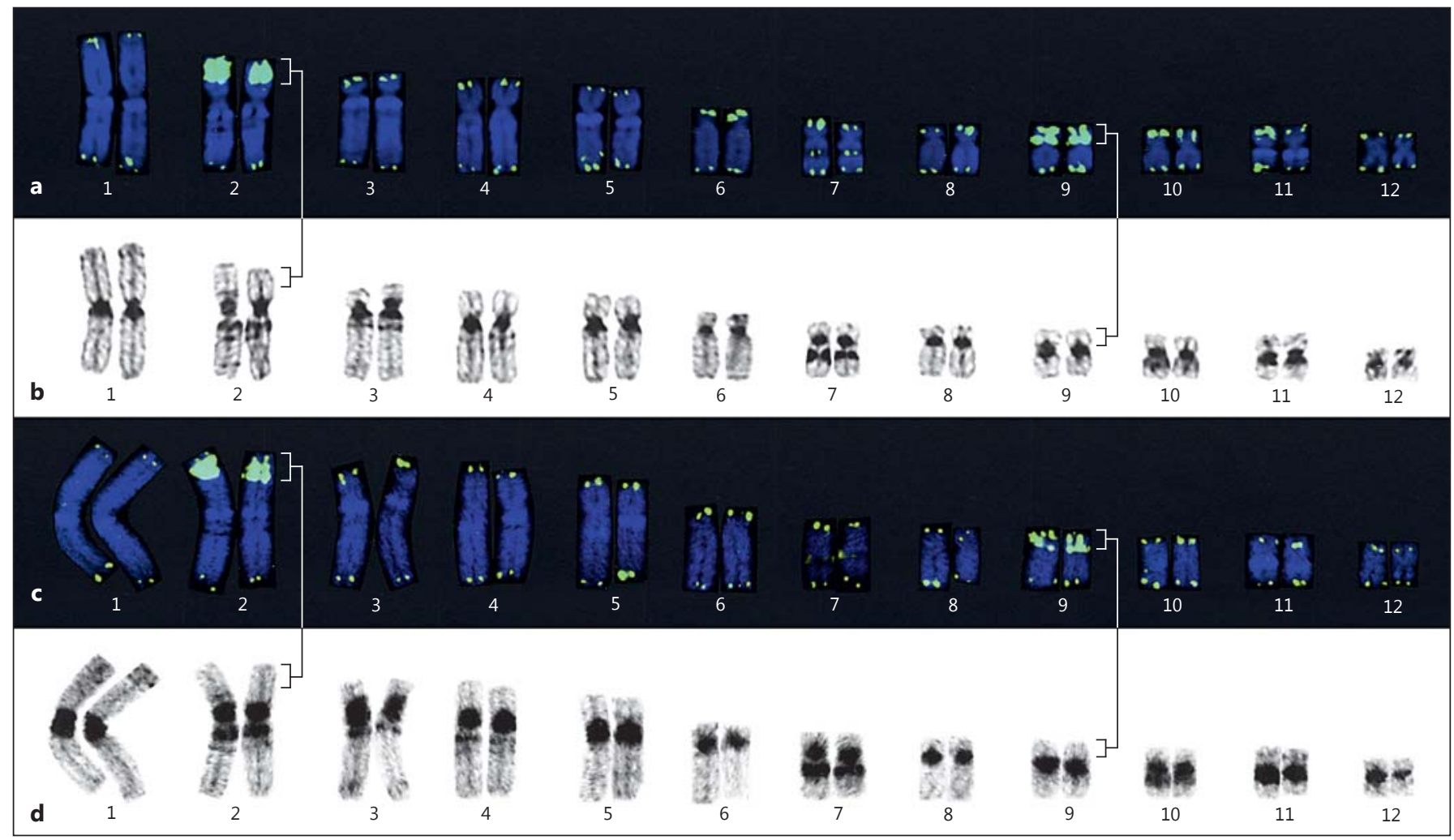

Fig. 5. Two karyotypes of Hypsiboas boans showing FISH with the telomeric DNA probe (a, c) and subsequent C-banding (b, d). The position of the 2 large restricted eu-ITSs in the short arms of chromosomes 2 and 9 is indicated by square brackets. Note that these large restricted eu-ITSs are clearly located in C-band-negative (euchromatic) regions.

het-ITSs commonly found in other amphibians and vertebrates. This may be attributed to the lower resolution of the C-band patterns together with the higher degree of chromosome condensation obtained in their study, and because they did not perform C-banding followed by FISH with the (TTAGGG) ${ }_{n}$ repeat on the same metaphases.

Table 1 lists the other Anura with restricted eu-ITSs detected up to date. Like $H$. boans and $H$. wavrini, the Brazilian hylid Sphaenorhynchus lacteus possesses a very prominent restricted eu-ITS located in the same site of the chromosome 2 short arm. Unless no further species of the phylogenetically distant genera Hypsiboas and Sphaenorhynchus are cytogenetically analyzed with telomeric DNA repeats, it cannot be decided if this is a mere coincidence or a very ancient and highly conserved cluster of ITSs in some lineages of the family Hylidae. On the other hand, the smaller restricted eu-ITSs present in interstitial regions of chromosomes 4 and 8 of the phylogenetically closely related Hyla cinerea, $H$. femoralis and $H$. squirella, and in the chromosomes 4, 7 and 11 of Pseudacris brimleyi and P. nigrita are homeologous and with high probability represent evolutionarily conserved markers that can be traced back to the karyotypes of common ancestors.

\section{Large ITSs in Dispersed Euchromatic Regions}

(Dispersed eu-ITSs)

The only examples of this category of ITSs hitherto found in anurans are present in 2 closely related North American treefrogs, the diploid $H$. chrysoscelis $(2 \mathrm{n}=24)$ and the tetraploid $H$. versicolor $(4 \mathrm{n}=48)$ as well as in their natural hybrid $(3 n=36)$ (table 1$)$. In their karyotypes dispersed eu-ITSs are located in, respectively, 26, 52 and 39 interstitial sites in the short and/or long arms of 9 chromosome pairs. In the diploid $H$. chrysoscelis, 1 dispersed eu-ITS close to the centromeric region in the chromosome 1 long arm occurs in heterozygous $(+/-)$ and homozygous ( $+/+$ and $-/-)$ conditions among the individuals of different populations. As in the case of the restricted 
het-ITS in the karyotype of Q. boulengeri (see above), the low number of specimens analyzed does not allow to calculate if the 3 karyomorphs of chromosome 1 are in Hardy-Weinberg equilibrium in the diploid $H$. chrysoscelis population. In the tetraploid $H$. versicolor, some specimens displayed this dispersed eu-ITS in 2 of the 4 homologues of chromosome 1, but in individuals of another population it was absent. Finally, in the single triploid $H$. chrysoscelis $\times H$. versicolor hybrid examined, this dispersed eu-ITS was found in 1 of the 3 homologues. According to the C-banding analyses of Anderson [1986, 1991], no visible constitutive heterochromatin is detectable in those chromosome regions where the 9 dispersed ITSs of $H$. chrysoscelis and $H$. versicolor are located. Therefore, these 9 dispersed ITSs can be classified as genuine dispersed eu-ITSs. The close relationship of the tetraploid $H$. versicolor and its diploid progenitor, $H$. chrysoscelis, explains the identical distribution patterns of the 9 dispersed ITSs in their karyotypes.

\section{Discussion}

In the karyotypes of 55 out of 100 vertebrate species examined in the pioneering studies of Meyne et al. [1989, 1990], at least 1 large ITS was found. Further conspicuous ITSs have been discovered in primates [Garagna et al., 1997; Go et al., 2000; Farré et al., 2009], Carnivora [Wurster-Hill et al., 1988], Cetartiodactyla [Scherthan, 1990; Lee et al., 1993; Vermeesch et al., 1996], Perissodactyla [Santani et al., 2002], Chiroptera [Finato et al., 2000], Rodentia [Bertoni et al., 1996; Fagundes and Yonenaga-Yassuda, 1998; Castiglia et al., 2006; Ventura et al., 2006, 2009; Swier et al., 2012; Nagamachi et al., 2013], Marsupialia [Metcalfe et al., 1998, 2002, 2007; Pagnozzi et al., 2000], birds [Nanda and Schmid, 1994; Nanda et al., 2002, 2007], reptiles [Schmid et al., 1994, 2014a; Pellegrino et al., 1999, 2009; Bertolotto et al., 2001; Srikulnath et al., 2009; Rovatsos et al., 2015], amphibians (table 1), and fishes [Abuín et al., 1996; Garrido-Ramos et al., 1998; Ocalewicz, 2013].

Concerning the origin of restricted het-ITSs, it is conceivable that they are relics of chromosomal repatternings that occurred during karyotype evolution and which have shifted telomeric (TTAGGG) ${ }_{\mathrm{n}}$ repeats into internal positions. From a theoretical point of view, those chromosome rearrangements capable of internalizing telomeric (TTAGGG) ${ }_{\mathrm{n}}$ repeats are mainly centric (Robertsonian) fusions, followed by inversions, tandem translocations and insertions [for review, see Schmid et al., 2010].
Definitely several of the many restricted het-ITSs found in vertebrates can be traced back to such chromosomal rearrangements which became fixed during karyotype evolution.

However, in the case of the dispersed het-ITSs of the frog $H$. faber and certain other vertebrates (see below), it is impossible that so many (TTAGGG) repeats, as estimated by the size and fluorescence intensity of the hybridization signals in the centromeric regions, have originated exclusively by centric fusions (compare size of telomeric and centromeric hybridization signals in fig. $3 g$ ). In the most favorable event, i.e., in case of a perfect telomeric fusion without terminal breaks or deletions, just a doubling of the telomeric hybridization signals, but not the observed remarkably large centromeric hybridization signals would be detected. Moreover, the karyotype of $H$. faber conforms to those of the vast majority of species in the family Hylidae, which all have diploid chromosome numbers of $2 \mathrm{n}=24$, fundamental numbers of FN $=48$, and highly conserved chromosome morphologies. Therefore, the karyotype of $H$. faber was certainly not derived by a series of repeated centric fusions. As already proposed by Meyne et al. [1990], an alternative and more satisfactory explanation is that in the centromeric heterochromatin of such chromosomes the (TTAGGG) repeats are merely a major component in the repetitive DNA of the heterochromatin itself. The (TTAGGG) ${ }_{n}$ repeat is known to be a main motif of the repetitive satellite DNAs of some vertebrates [Southern, 1970; Fry and Salser, 1977; Arnason et al., 1988; Arnason and Widegren, 1989; Adegoke et al., 1993; Garrido-Ramos et al., 1998; Rovatsos et al., 2011]. In other words, a partial or complete sequence identity of the telomeric DNA and the repetitive DNA in these heterochromatic regions is purely coincidental.

The same patterns of dispersed het-ITSs as occurring in $H$. faber were discovered in 3 exceptional lizards of the family Sphaerodactylidae. The karyotypes of Gonatodes falconensis and G. taniae from Venezuela are distinguished by the extraordinarily reduced chromosome number of $2 n=16$, which is the lowest value found in reptiles up to date. Both species are characterized by considerable amounts of (TTAGGG) ${ }_{n}$ sequences in the centromeric regions of all 8 chromosome pairs [Schmid et al., 1994, 2014a]. In contrast, the Mediterranean Euleptes europea has $2 \mathrm{n}=42$ chromosomes, which is the highest value so far detected in the family Sphaerodactylidae, as well as one of the highest among all lizards. Also in this lizard, large amounts of (TTAGGG) $)_{n}$ sequences are located the centromeric regions of all telocentric/subtelocentric 21 
Table 2. A proposed formal classification of the known categories of (TTAGGG) $)_{n}$ repeats in vertebrate genomes, their locations in chromosomes and distribution patterns

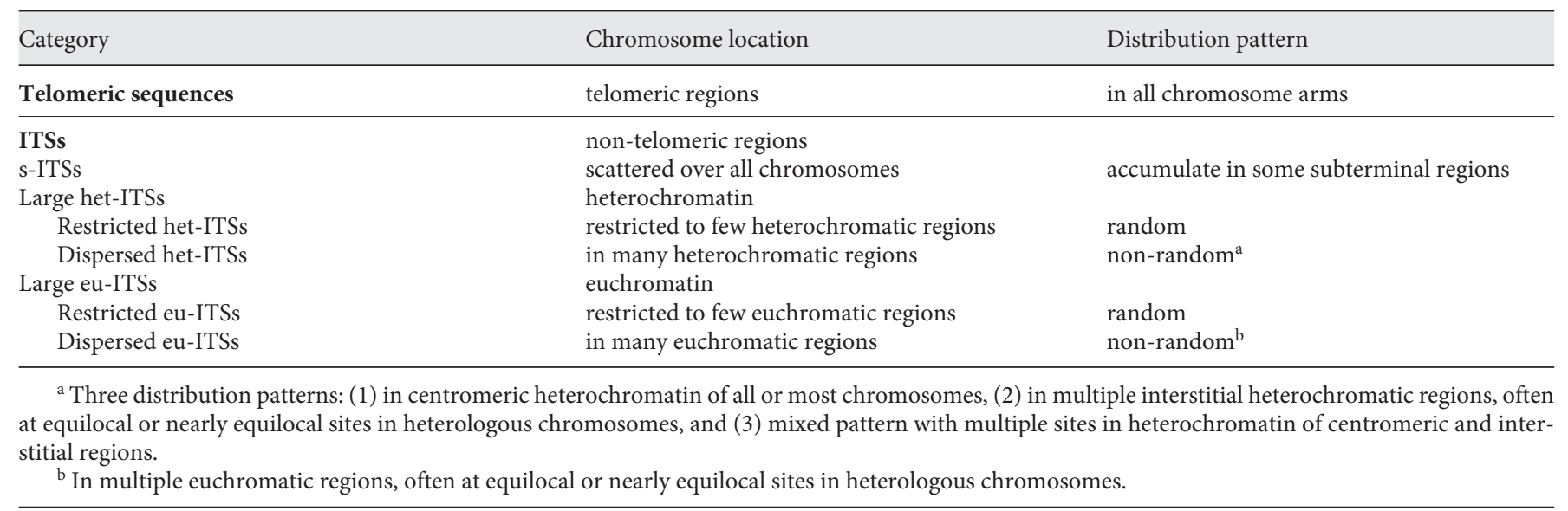

chromosome pairs [Gornung et al., 2013]. Furthermore, in the lizards Aspidoscelis sexlineata and A. gularis of the family Teidae, (TTAGGG) ${ }_{n}$ sequences colocalize with the centromeric heterochromatin of most chromosomes [Meyne et al., 1990]. The best studied dispersed het-ITSs are those of the Chinese hamster (Cricetulus griseus). In this species dispersed het-ITSs are a major constituent of the repetitive satellite DNA [Faravelli et al., 1998, 2002], which is located in the centromeric and pericentromeric regions of most chromosomes and which comprises about $5 \%$ of the hamster genome [Day et al., 1998]. These dispersed het-ITSs are arranged as extended tandem arrays that are not interrupted by any other sequences and do not contain restriction enzyme cleavage sites [Faravelli et al., 2002].

The question arises about the molecular structure and origin of eu-ITSs. It is possible that under certain conditions and promoted by whatsoever event(s), s-ITSs in nonheterochromatic (euchromatic) chromosome regions can amplify excessively and extend into adjacent chromosome segments. This massive amplification could cause a size increase of the affected chromosome arm and change the original chromosome morphology. It is further tempting to hypothesize that transposable elements which are closely linked to telomeric (TTAGGG) ${ }_{\mathrm{n}}$ repeats spread by transposition carrying complete or partial (TTAGGG) $)_{\mathrm{n}}$ repeats and preferentially integrate into the chromosomal DNA of specific euchromatic regions containing appropriate target sites. In both cases, large numbers of reiterated sequences would accumulate and form a chromosome region with highly repetitive DNA which can further degenerate and, in turn, form constitutive heterochromatin detectable by the classical C-banding technique.

In several stages of mitosis and meiosis there is an alignment of the chromosomes with the centromeres grouped together in one part of the cell and their telomeres at the opposite side (Rabl-orientation). It has been proposed that this arrangement, together with unequal crossover, transposition and amplification, leads to an equilocal spreading of constitutive heterochromatin throughout the genomes [Greilhuber and Loidl, 1983; Schweizer and Loidl, 1987]. This explains why in many species constitutive heterochromatin is located in the same or nearly the same relative regions in different chromosomes. By the same mechanism, both het-ITSs and eu-ITSs can multiply in a concerted manner throughout the genomes and reach equilocal sites in heterologous chromosomes. The dispersed het-ITSs found in centromeric and interstitial regions, as well as the dispersed eu-ITSs localized in interstitial regions of anuran chromosomes (table 1) could have evolved in this way.

A formal classification of the different categories of (TTAGGG) $)_{n}$ repeats in vertebrate genomes, based on their locations in chromosomes and distribution patterns is presented in table 2. Up to date, the anuran species analyzed by telomeric sequence mapping represent only a very small fraction of all recognized species. In order to substantiate this ITS classification, it is mandatory that much more species, representative of all genera, must be studied by FISH with the telomeric (TTAGGG) $n$ repeat. These experiments must be extended to the chromosomes of species belonging to the amphibian orders Urodela and Apoda. 


\section{Acknowledgements}

We thank Dr. Max King and Dr. Michael Mahony (Australia), Dr. Willy Beçak and Dr. Maria Luisa Beçak (Brazil) and Dr. Alberto Fernández Badillo (Venezuela) for logistic help during our expeditions to these countries. The very expert and reliable photographic assistance of Gitta Hesse is highly appreciated. This study was financially supported by the German Research Foundation, DFG (grants Schm 484/6-1 and Schm484/10-1), the DAAD-CNPq (grant 322), and the Volkswagen Foundation (grant VW/I/72 515).

\section{Statement of Ethics}

All procedures with the living animals strictly conformed to the guidelines established by the Animal Care Committees of the respective countries.

\section{Disclosure Statement}

The authors have no conflicts of interest to declare.

\section{References}

Abuín M, Martínez P, Sánchez L: Localization of Brunes TO, Sequeira F, Haddad CFB, Alexandrithe repetitive telomeric sequence (TTAGGG) in four salmonid species. Genome 39:10351038 (1996).

Adegoke JA Arnason U, Widegren B: Sequence organization and evolution, in all extant whalebone whales, of a satellite DNA with terminal chromosome localization. Chromosoma 102:382-388 (1993).

Anderson K: A Cytotaxonomic Analysis of the Holarctic Treefrogs in the Genus Hyla. PhD thesis, University of New York (1986).

Anderson K: Chromosome evolution in Holarctic treefrogs, in Green DM, Sessions SK (eds): Amphibian Cytogenetics and Evolution, pp 299-331 (Academic Press, San Diego 1991).

-Arnason U, Widegren B: Composition and chromosomal localization of cetacean highly repetitive DNA with special reference to the blue whale, Balaenoptera musculus. Chromosoma 98:323-329 (1989).

-Arnason U, Allerdice PW, Lien J, Widegren B: Highly repetitive DNA in the baleen whale genera Balaenoptera and Megaptera. J Mol Evol 27:217-221 (1988).

-Azzalin CM, Mucciolo E, Bertoni L, Giulotto E: Fluorescence in situ hybridization with a synthetic (T2AG3) n polynucleotide detects several intra-chromosomal telomere-like repeats on human chromosomes. Cytogenet Cell Genet 78:112-115 (1997).

-Azzalin CM, Nergadze SG, Giulotto E: Human intrachromosomal telomeric-like repeats: sequence organization and mechanisms of origin. Chromosoma 110:75-82 (2001).

Barth A, Vences M, Solé M, Costa MA: Molecular cytogenetics and phylogenetic analysis of Brazilian leaf frog species of the genera Phyllomedusa and Phasmahyla (Hylidae: Phyllomedusinae). Can J Zool 92:795-802 (2014).

Bertolotto CEV, Rodrigues MT, Yonenaga-Yassuda Y: Banding patterns, multiple sex chromosome system and localization of telomeric (TTAGGG) $)_{n}$ sequences by FISH on two species of Polychrus (Squamata, Polychrotidae). Caryologia 54:217-226 (2001).

Bertoni L, Attolini C, Faravelli M, Simi S, Giulotto E: Intrachromosomal telomere-like DNA sequences in Chinese hamster. Mamm Genome 7:853-855 (1996). no J: Gene and species trees of a Neotropical group of treefrogs: genetic diversification in the Brazilian Atlantic Forest and the origin of a polyploid species. Mol Phylogenet Evol 57: 1120-1133 (2010)

Bruschi DP, Rivera M, Lima AP, Zuñiga AB, Recco-Pimentel SM: Interstitial telomeric sequences (ITS) and major rDNA mapping reveal insights into the karyotypical evolution of neotropical leaf frogs species (Phyllomedusa, Hylidae, Anura). Mol Cytogenet 7:22 (2014).

Camats N, Ruiz-Herrera A, Parrilla JJ, Acien N, Payá $\mathrm{P}$, et al: Genomic instability in rat: breakpoints induced by ionising radiation and interstitial telomere-like sequences. Mutat Res 595:156-166 (2006)

Carvalho KA, Garcia PCA, Recco-Pimentel SM: NOR dispersion, telomeric sequence detection in centromeric regions and meiotic multivalent configurations in species of the Aplastodiscus albofrenatus group (Anura, Hylidae). Cytogenet Genome Res 126:359-367 (2009).

Castiglia R, Garagna S, Merico V, Oguge N, Corti M: Cytogenetics of a new cytotype of African Mus (subgenus Nannomys) minutoides (Rodentia, Muridae) from Kenya: C- and Gbanding and distribution of (TTAGGG) telomeric sequences. Chromosome Res 14: 587-594 (2006).

Day JP, Limoli CL, Morgan WF: Recombination involving interstitial telomere repeat-like sequences promotes chromosomal instability in Chinese hamster cells. Carcinogenesis 19: 259-265 (1998).

de Mattos TL, Coelho AC, Schneider CH, Telles DOC, Menin M, Gross MC: Karyotypic diversity in seven Amazonian anurans in the genus Hypsiboas (family Hylidae). BMC Genetics 15:43 (2014).

Fagundes V, Yonenaga-Yassuda Y: Evolutionary conservation of whole homoeologous chromosome arms in the akodont rodents Bolomys and Akodon (Muridae, Sigmodontinae): maintenance of interstitial telomeric segments (ITSs) in recent event of centric fusion. Chromosome Res 6:643-648 (1998).

Faivovich J, Haddad CFB, Garcia PCA, Frost DR, Campbell JA, Wheeler WC: Systematic re- view of the frog family Hylidae, with special reference to Hylinae: phylogenetic analysis and taxonomic revision. Bull Am Mus Nat Hist 294:1-240 (2005).

Faravelli M, Moralli D, Bertoni L, Attolini C, Chernova O, et al: Two extended arrays of a satellite DNA sequence at the centromere and the short-arm telomere of Chinese hamster chromosome 5. Cytogenet Cell Genet 83:281286 (1998).

Faravelli M, Azzalin CM, Bertoni L, Chernova O, Attolini C, et al: Molecular organization of internal telomeric sequences in Chinese hamster chromosomes. Gene 283:11-16 (2002).

Farré M, Ponsà M, Bosch M: Interstitial telomeric sequences (ITSs) are not located at the exact evolutionary breakpoints in primates. Cytogenet Genome Res 124:128-131 (2009).

Finato AO, Varella-Garcia M, Tajara EH, Taddei VA, Morielle-Versute E: Intrachromosomal distribution of telomeric repeats in Eumops glaucinus and Euntops perotis (Molossidae, Chiroptera). Chromosome Res 8:563-569 (2000).

Fry K, Salser W: Nucleotide sequences of HS- $\alpha$ satellite DNA from kangaroo rat Dipodomys ordii and characterization of similar sequences in other rodents. Cell 12:1069-1084 (1977).

Garagna S, Ronchetti E, Mascheretti S, Crovella S, Formenti D, et al: Non-telomeric chromosome localization of (TTAGGG) ${ }_{n}$ repeats in the genus Eulemur. Chromosome Res 5:487491 (1997).

Garrido-Ramos MA, Herrán R, Rejón R, Rejón MR: A satellite DNA of the Sparidae family (Pisces, Perciformes) associated with telomeric sequences. Cytogenet Cell Genet 83: 3-9 (1998).

Gazoni T, Gruber SL, Silva APZ, Araújo OGS, Narimatsu H, et al: Cytogenetic analyses of eight species in the genus Leptodactylus Fitzinger, 1843 (Amphibia, Anura, Leptodactylidae), including a new diploid number and a karyotype with multiple translocations. BMC Genet 13:109 (2012).

Go Y, Rakotoarisoa G, Kawamoto Y, Randrianjafy A, Koyama N, Hirai H: PRINS analysis of the telomeric sequence in seven lemurs. Chromosome Res 8:57-65 (2000). 
Gornung E, Mosconi F, Annesi F, Castiglia R: The first cytogenetic description of Euleptes europaea (Gené, 1839) from Northern Sardinia reveals the highest diploid chromosome number among sphaerodactylid geckos (Sphaerodactylidae, Squamata). Comp Cytogenet 7: 153-161 (2013).

Gregory TR, Mable BK: Polyploidy in animals, in Gregory TR (ed): The Evolution of the Genome, pp 427-517 (Elsevier Academic Press, Burlington 2005).

Greilhuber J, Loidl J: On regularities of C-banding patterns and their possible cause, in Brandham PE, Bennett MD (eds): Kew Chromosome Conference II, p 344 (Allen and Unwin, London 1983).

- Gruber SL, Haddad CFB, Kasahara S: Karyotype analysis of seven species of the tribe Lophiohylini (Hylinae, Hylidae, Anura), with conventional and molecular cytogenetic techniques. Comp Cytogenet 6:409-423 (2012a).

- Gruber SL, Zina J, Narimatsu H, Haddad CFB, Kasahara S: Comparative karyotype analysis and chromosome evolution in the genus Aplastodiscus (Cophomantini, Hylinae, Hylidae). BMC Genet 13:28 (2012b).

- Gruber SL, Silva APZ, Haddad CFP, Kasahara S: Cytogenetic analysis of Phyllomedusa distincta Lutz, $1950(2 \mathrm{n}=2 \mathrm{x}=26)$, $P$. tetraploidea Pombal and Haddad, $1992(2 \mathrm{n}=4 \mathrm{x}=52)$, and their natural triploid hybrids $(2 \mathrm{n}=3 \mathrm{x}=39)$ (Anura, Hylidae, Phyllomedusidae). BMC Genetics 14:75 (2013).

Lee C, Sasi R, Lin CC: Interstitial localization of telomeric DNA sequences in the Indian muntjac chromosomes: further evidence for tandem chromosome fusions in the karyotypic evolution of the Asian muntjacs. Cytogenet Cell Genet 63:156-159 (1993).

Leipoldt M: Towards an understanding of the molecular mechanisms regulating gene expression during diploidization in phylogenetically polyploid lower vertebrates. Hum Genet 65:11-18 (1983).

- Metcalfe CJ, Eldridge MD, Toder R, Johnston PG: Mapping the distribution of the telomeric sequence (T2AG3) $\mathrm{n}$ in the Macropodoidea (Marsupialia), by fluorescence in situ hybridization. I. The swamp wallaby, Wallabia bicolor. Chromosome Res 6:603-610 (1998).

- Metcalfe CJ, Eldridge MD, Johnston PG: Mapping the distribution of the telomeric sequence $(\mathrm{T}(2) \mathrm{AG}(3))(\mathrm{n})$ in rock wallabies, Petrogale (Marsupialia: Macropodidae), by fluorescence in situ hybridization. ii. The lateralis complex. Cytogenet Genome Res 96: 169-175 (2002).

Metcalfe CJ, Eldridge MD, Johnston PG: Mapping the distribution of the telomeric sequence $(\mathrm{T} 2 \mathrm{AG} 3)_{\mathrm{n}}$ in Macropodoidea (Marsupialia) by fluorescence in situ hybridization. II. The ancestral 2n = 22 macropodid karyotype. Cytogenet Genome Res 116:212-217 (2007).

Meyne J, Ratliff RL, Moyzis RK: Conservation of the human telomere sequence (TTAGGG) among vertebrates. Proc Natl Acad Sci USA 86:7049-7053 (1989).
Meyne J, Baker RJ, Hobart HH, Hsu TC, Ryder OA, et al: Distribution of non-telomeric sites of the (TTAGGG) $)_{n}$ telomeric sequence in vertebrate chromosomes. Chromosoma 99:3-10 (1990).

-Nagamachi CY, Pieczarka JC, O’Brien PC, Pinto JA, Malcher SM, et al: FISH with whole chromosome and telomeric probes demonstrates huge karyotypic reorganization with ITS between two species of Oryzomyini (Sigmodontinae, Rodentia): Hylaeamys megacephalus probes on Cerradomys langguthi karyotype. Chromosome Res 21:107-119 (2013).

Nanda I, Schmid M: Localization of the telomeric (TTAGGG) $)_{\mathrm{n}}$ sequence in chicken (Gallus domesticus) chromosomes. Cytogenet Cell Genet 65:190-193 (1994).

Nanda I, Schrama D, Feichtinger W, Haaf T, Schartl M, Schmid M: Distribution of telomeric (TTAGGG) ${ }_{\mathrm{n}}$ sequences in avian chromosomes. Chromosoma 111:215-227 (2002).

Nanda I, Karl E, Griffin DK, Schartl M, Schmid $\mathrm{M}$ : Chromosome repatterning in three representative parrots (Psittaciformes) inferred from comparative chromosome painting. $\mathrm{Cy}-$ togenet Genome Res 117:43-53 (2007).

Nanda I, Fugate M, Steinlein C, Schmid M: Distribution of (TTAGGG) $)_{n}$ telomeric sequences in karyotypes of the Xenopus species complex. Cytogenet Genome Res 122:396-400 (2008).

$\rightarrow$ Nergadze SG, Rocchi M, Azzalin CM, Mondello C, Giulotto E: Insertion of telomeric repeats at intrachromosomal break sites during primate evolution. Genome Res 14:1704-1710 (2004).

Nergadze SG, Santagostino MA, Salzano A, Mondello C, Giulotto E: Contribution of telomerase RNA retrotranscription to DNA doublestrand break repair during mammalian genome evolution. Genome Biol 8:R260 (2007).

Ocalewicz K: Telomeres in fishes. Cytogenet Genome Res 141:114-125 (2013).

Ohno S: Evolution by Gene Duplication (Springer, Berlin 1970).

Pagnozzi JM, De Jesus Silva MJ, Yonenaga-Yassuda Y: Intraspecific variation in the distribution of the interstitial telomeric (TTAGGG) sequences in Micoureus demerarae (Marsupialia: Didelphidae). Chromosome Res 8: 585-591 (2000).

Pellegrino KCM, Rodrigues MT, Yonenaga-Yassuda Y: Chromosomal evolution in the Brazilian lizards of genus Leposoma (Squamata, Gymnophthalmidae) from Amazon and Atlantic rain forests: banding patterns and FISH of telomeric sequences. Hereditas 131:15-21 (1999).

- Pellegrino KCM, dos Santos RML, Rodrigues MT, Laguna MM, Amaro RC, Yonenaga-Yassuda Y: Chromosomal evolution in the Brazilian geckos of the genus Gymnodactylus (Squamata, Phyllodactylidae) from the biomes of Cerrado, Caatinga and Atlantic rain forest: evidence of Robertsonian fusion events and supernumerary chromosomes. Cytogenet Genome Res 127:191-203 (2009).
Pombal JP, Haddad CFB: Espécies de Phyllomedusa do grupo burmeisteri do Brasil oriental, com descrição de uma espécie nova (Amphibia, Hylidae). Rev Bras Biol 52:217-229 (1992).

Qing L, Xia Y, Zheng Y, Zeng X: A de novo case of floating chromosomal polymorphisms by translocation in Quasipaa boulengeri (Anura, Dicroglossidae). PLoS One 7:e46163 (2012).

Qing L, Xia Y, Zheng Y, Zeng X: FISH of 5S rDNA and telomeric (TAAGGG) $)_{n}$ repeats in normal and translocated populations of the frog Quasipaa boulengeri (Anura, Ranidae). Chin Sci Bull 58:2168-2173 (2013).

Rovatsos MT, Marchal JA, Romero-Fernández I, Fernández FJ, Giagia-Athanosopoulou EB, Sánchez A: Rapid, independent, and extensive amplification of telomeric repeats in pericentromeric regions in karyotypes of arvicoline rodents. Chromosome Res 19:869-882 (2011).

Rovatsos M, Kratochvil L, Altmanova M, Johnson Pokorna M: Interstitial telomeric motifs in squamate reptiles: when the exceptions outnumber the rule. PLoS One 10:e134985 (2015).

Ruiz-Herrera A, García F, Azzalin C, Giulotto E, Egozcue J, et al: Distribution of intrachromosomal telomeric sequences (ITS) on Macaca fascicularis (Primates) chromosomes and their implication for chromosome evolution. Hum Genet 110:578-586 (2002).

Ruiz-Herrera A, García F, Giulotto E, Attolini C, Egozcue J, et al: Evolutionary breakpoints are co-localized with fragile sites and intrachromosomal telomeric sequences in primates. Cytogenet Genome Res 108:234-247 (2005).

Ruiz-Herrera A, Nergadze SG, Santagostino M, Giulotto E: Telomeric repeats far from the ends: mechanisms of origin and role in evolution. Cytogenet Genome Res 122:219-228 (2008).

-Santani A, Raudsepp T, Chowdhary BP: Interstitial telomeric sites and NORs in Hartmann's zebra (Equus zebra hartmannae) chromosomes. Chromosome Res 10:527-534 (2002).

Scherthan H: Localization of the repetitive telomeric sequence (TTAGGG) ${ }_{n}$ in two muntjak species and implications for their karyotypic evolution. Cytogenet Cell Genet 53:115-117 (1990).

-Schmid M, Feichtinger W, Nanda I, Schakowski R, Visbal García R, et al: An extraordinarily low diploid chromosome number in the reptile Gonatodes taniae (Squamata, Gekkonidae). J Hered 85:255-260 (1994).

-Schmid M, Feichtinger W, Steinlein C, Visbal García R, Fernández Badillo A: Chromosome banding in Amphibia. XXVIII. Homomorphic XY sex chromosomes and a derived Yautosome translocation in Eleutherodactylus riveroi (Anura, Leptodactylidae). Cytogenet Genome Res 101:62-73 (2003).

Schmid M, Steinlein C, Bogart JP, Feichtinger W, León $\mathrm{P}$, et al: The chromosomes of terraranan frogs. Insights into vertebrate cytogenetics. Cytogenet Genome Res 130/131:1-568 (2010). 
-Schmid M, Steinlein C, Feichtinger W, Haaf T, Mijares-Urrutia A, et al: Cytogenetic studies on Gonatodes (Reptilia, Squamata, Sphaerodactylidae). Cytogenet Genome Res 144:4761 (2014a).

Schmid M, Steinlein C, Feichtinger W, Bogart JP Chromosome banding in Amphibia. XXXI. The neotropical anuran families Centrolenidae and Allophrynidae. Cytogenet Genome Res 142:268-285 (2014b).

Schweizer D, Loidl J: A model for heterochromatin dispersion and the evolution of C-band patterns, in Stahl A, Luciani JM, Vagner-Capodano AM (eds): Chromosomes Today, Vol 9, pp 61-79 (Allen and Unwin, London 1987).

-Southern EM: Base sequence and evolution of guinea-pig $\alpha$-satellite DNA. Nature 227:794798 (1970).

-Srikulnath K, Matsubara K, Uno Y, Thongpan A Suputtitada S, et al: Karyological characterization of the butterfly lizard (Leiolepis reevesii rubritaeniata, Agamidae, Squamata) by molecular cytogenetic approach. Cytogenet Genome Res 125:213-223 (2009).
- Suárez P, Cardozo D, Baldo D, Pereyra MO, Faivovich J, et al: Chromosome evolution in Dendropsophini (Amphibia, Anura, Hylinae). Cytogenet Genome Res 141:295-308 (2013).

Swier VJ, Khan FAA, Baker R: Do time, heterochromatin, NORs, or chromosomal rearrangements correlate with distribution of interstitial telomeric repeats in Sigmodon (cotton rats)? J Hered 103:493-502 (2012).

Ventura K, Silva MJ, Fagundes V, Christoff AU, Yonenaga-Yassuda Y: Non-telomeric sites as evidence of chromosomal rearrangement and repetitive (TTAGGG) $)_{\mathrm{n}}$ arrays in heterochromatic and euchromatic regions in four species of Akodon (Rodentia, Muridae). Cytogenet Genome Res 115:169-175 (2006).

-Ventura K, O'Brien PCM, Yonenaga-Yassuda Y, Ferguson-Smith MA: Chromosome homologies of the highly rearranged karyotypes of four Akodon species (Rodentia, Cricetidae) resolved by reciprocal chromosome painting: the evolution of the lowest diploid number in rodents. Chromosome Res 17:1063-1078 (2009).
Vermeesch JR, De Meurichy W, Van den Berghe $\mathrm{H}$, Marynen P, Petit P: Differences in the distribution and nature of the interstitial telomeric (TTAGGG) $)_{\mathrm{n}}$ sequences in the chromosomes of the Giraffidae, okapi (Okapia johnstoni), and giraffe (Giraffa camelopardalis): evidence for ancestral telomeres at the okapi polymorphic rob $(5 ; 26)$ fusion site. Cytogenet Cell Genet 72:310-315 (1996).

-Wiley JE, Meyne J, Little ML, Stout JC: Interstitial hybridization sites of the (TTAGGG) telomeric sequence on the chromosomes of some North American hylid frogs. Cytogenet Cell Genet 61:55-57 (1992).

Wurster-Hill DH, Ward OG, Davis BH, Park JP, Moyzis RK, Meyne J: Fragile sites, telomeric DNA sequences, B chromosomes, and DNA content in raccoon dogs, Nyctereutes procyonoides, with comparative notes on foxes, coyote, wolf, and raccoon. Cytogenet Cell Genet 49:278-281 (1988) 